\title{
El origen del café en México y el incremento de su producción en Chiapas, 1893-1920
}

Elías Gaona Rivera, Profesor Investigador, Universidad Autónoma del Estado de Hidalgo. Email: elias_gaona3473@uaeh.edu.mx. ORCID_ID: 0000-0003-2630-219X

Angélica María Vázquez Rojas; Profesora Investigadora, Universidad Autónoma del Estado de Hidalgo. ORCID_ID: 0000-0003-2907-5383

Eduardo Rodríguez Juárez, Profesor Investigador, Universidad Autónoma del Estado de Hidalgo. ORCID_ID: 0000-0002-2232-7544

Fechas del Artículo:

Recibido: 03/05/2020

Dictamen: 06/06/2020

Aceptado: 24/09/2020

Publicado: $30 / 10 / 2020$
Forma de citar este artículo: Gaona E., Vázquez A.M. y

Rodríguez E., (2020). El origen del café en México y el incremento de su producción en Chiapas, 1893-1920, Revista Científica de Estudios Urbano Regionales HatsöHnini, Vol 1 No. 3 pp.14-23, DOI https:// doi.org/10.47386/2020V1N3A2

\section{Resumen}

El artículo tiene por objetivo estudiar el arribo del café a México y a Chiapas y analizar cómo se incrementó la producción de café en el estado del sur, gracias a dos factores: la baratura de la tierra y la llegada de inversión extrajera, fundamentalmente de Estados Unidos y de Alemania. La hipótesis de este trabajo es que el incremento de la producción de café en Chiapas, entre 1893-1920, obedeció a la venta de tierras a precios baratos y al arribo de inversión extranjera esencialmente de origen alemán y estadounidense. La metodología utilizada fue la histórica. Este tipo de investigación busca reconstruir el pasado de la manera más objetiva y exacta posible, a través de examinar documentos y periodos del pasado. Este método, en lugar de observar directamente hechos, actúa indirectamente estudiando documentos y periódicos, en este caso en particular nos apoyamos de periódicos mexicanos y estadounidenses, de la época. Se concluye que Chiapas se posicionó como uno de los principales estados productores de café del país debido a dos razones: el bajo costo de la tierra para sembrar y la llegada de inversión extranjera.

Palabras clave: México, Chiapas, café, precio de la tierra e inversión extranjera.

\section{Abstract}

The article aims to study the arrival of coffee to Mexico and Chiapas and to analyze how coffee production increased in the southern state, thanks to two factors: the cheapness of land and the arrival of for-

\section{|||||||| \\ REDMIIDUS}

eign investment, mainly from the United States and from Germany. The hypothesis of this work is that the increase in coffee production in Chiapas, between1893-1920, was due to the sale of land at cheap prices and the arrival of foreign investment essentially of German and American origin. The methodology used was the historical one. This type of research seeks to reconstruct the past in the most objective and exact way possible, through examining documents and periods of the past. This method, instead of directly observing facts, acts indirectly by studying documents and newspapers, in this particular case we rely on Mexican and American newspapers of the time. It is concluded that Chiapas positioned itself as one of the main coffee producing states in the country due to two reasons: the low cost of land to plant and the arrival of foreign investment.

Keywords: Mexico, Chiapas, coffee, land prices and foreign investment.

\section{Introducción}

El objetivo de este trabajo es analizar de qué manera llegó el café a México, desde cuándo y en particular a Chiapas; también cómo es que, gracias al bajo costo de la tierra, en el estado del sur, y al arribo de la inversión extrajera, la producción del café se incrementó. De estos dos puntos, la aportación fundamental es el análisis del costo que tenía la tierra en Chiapas, en comparación con otras regiones de México.

Para el tema de la inversión, la información se extra- 
El origen del café en México y el incremento de su producción en Chiapas, 1893-1920

Elías Gaona Rivera, Angélica María Vázquez Rojas y Eduardo Rodríguez Juárez

jo fundamentalmente del excelente trabajo de investigación que realizó Tovar (2004), acerca de Los finqueros extranjeros en el Soconusco durante el porfiriato. De igual forma, para lograr los objetivos, se utilizaron periódicos mexicanos y estadounidenses, de la época, tales como: la Gaceta de México, El Águila Mexicana, la Semana mercantil, el Daily Alta California, y el California Farmer and Journal of Useful Science, entre otros.

Además, este trabajo aportará nueva información de diferentes ámbitos que se abordan, tales como: los principales países productores de café en 1892; las importaciones de café que México realizaba, desde Cuba, a partir de 1784 y hasta 1819, antes de que México fuera uno de los principales productores de café del mundo; y el año en que se estableció la primera cafetería en México, casi inmediatamente después de su independencia en 1824.

La metodología utilizada fue la histórica. Este tipo de investigación busca reconstruir el pasado de la manera más objetiva y exacta posible (Dzul, 2020: 3 ), a través de examinar documentos y periodos del pasado. Este método, en lugar de observar directamente hechos, actúa indirectamente estudiando documentos (Langlois y Seignobos, 2003: 30). Arriba señalamos, en cuales nos basaremos para realizar este trabajo.

El artículo está estructurado con los siguientes apartados: introducción, el café coloniza el mundo, el café se vuelve latino y el arribo del café a México y en particular a Chiapas, teniendo este último apartado dos subdivisiones: 1) el bajo costo de las tierras para cultivar y 2) la inversión extranjera; y finalmente las conclusiones.

\section{El café coloniza el mundo}

El mercadeo del café inició a principios del siglo XV, cuando fue introducido a Yemen, procedente de Abisinia -Etiopía-, donde era consumido como una bebida estimulante asociada a rituales religiosos, el cual con el transcurrir del tiempo se propagó por el mundo árabe. A mediados del siglo $\mathrm{XV}$ ya funcionaban cafeterías en las ciudades árabes más importantes, extendiéndose posteriormente hacia el resto del mundo musulmán (Pérez, 2013: 161). En el siglo XVI ya se conocía en Persia, Egipto, Siria y Turquía (National Coffee Association).

Los viajeros europeos que anduvieron por el Cercano Oriente llevaron historias de una inusual bebida negra oscura. El café llegó a Europa en el siglo XVII y pronto se volvió muy popular en todo el conti- nente. Algunas personas reaccionaron a esta nueva bebida con sospecha o miedo, llamándola la "invención amarga de Satanás". La polémica fue amplia, de tal forma que se le demandó al Papa Clemente VIII que intercediera. Resolvió probar el líquido por sí mismo antes de emitir un fallo, y la encontró tan grata que le dio el beneplácito papal. Señaló que sería una lástima que los infieles tuvieran un uso exclusivo (Pendergrast, 2010: 8).

A pesar del debate, los lugares en donde se vendía café se estaban volviendo velozmente en centros de dinamismo social, en las principales sus principales ciudades: Alemania, Austria, Holanda, Francia e Inglaterra. El café comenzó a reemplazar las bebidas de desayuno comunes de la época: la cerveza y el vino (National Coffee Association, 2020).

\section{El café se vuelve latino}

En 1714, los holandeses entregaron una planta de café saludable al gobierno francés, y nueve años después, el oficial naval francés, Gabriel Mathieu de Clieu, introdujo el cultivo del café en la colonia francesa de Martinica, en las Antillas. De igual forma, los colonos franceses cultivaron café por primera vez en San Domingo (Haití) en 1734. En 1788 esta isla suministró la mitad del café del mundo (Pendergrast, 2010:17). Antes de 1825, Cuba, Santo Domingo, las Antillas Británicas y Java eran los principales lugares de producción, posteriormente Brasil tomó la delantera. Desde 1830 hasta 1835, este país incrementó la producción de café en un grado nunca antes conocido, de tal forma, que ya para 1851 era el productor de casi la mitad de la producción (Tabla 1). En Cuba, se descubrió que el azúcar pagaba mejores ganancias a los plantadores, por lo que, alrededor de 1825, comenzó a descuidar el café (Daily Alta California, 1852).

El primer café consumido en la Nueva España fue de importación. Esto lo podemos deducir por los registros del Archivo General de la Nación producidos por el Real Tribunal del Consulado quien proporciona cuentas de maíz, paños, diversos géneros y café, durante el periodo de 1621-1624 ${ }^{1}$. De acuerdo con Vila (1997:85) su siembra se inició en 1790. Sin embargo, Humboldt (1822:378) señalaba que en la Nueva España había muchos trapiches, pero que el producto del café era nulo y que antes de 1803, su consumo todavía era raro en México.

\footnotetext{
1 AGN, Instituciones Coloniales/ Indiferente Virreinal/ Caja 5660/ Exp. 074.
} 
Amén de que su labranza tendría muy buena aceptación en los lugares templados, a la altura de Chilpancingo y Jalapa. Su consumo anual, según Humboldt era de 400 o 500 quintales (1 quintal es equivalente a $46.008 \mathrm{kgs}$.), es decir, 18.4 y 23.0 toneladas, respectivamente, teniendo un consumo promedio anual entre 50 y 63 kilogramos al día, incrementándose hasta alcanzar la cifra de 481.6 kilogramos en el año de $1817^{2}$. En este último año la importación de café fue de 175.8 toneladas, lo cual indica que el consumo de café, en la Nueva España, se estaba incrementando. El café provenía fundamentalmente de la Habana ${ }^{3}$

Sin embargo, es importante mencionar que se realizaron exportaciones de café de la Nueva España a España en los años de 1802 y 1804, pero seguramente estas exportaciones eran parte de lo que antes ya había importado la Nueva España y no era producción autóctona o hecha en territorio novohispano. En el texto de Lerdo de Tejada (1967) apare$\mathrm{ce}^{4}$ que en 1802 se importaron 344 quintales y con el título de reportación para España 272 quintales, es decir, que la mayor parte de lo que se importó de café, después se exportó, el 79\%, para España. En el año de 1804 menciona que se importaron de América (con probabilidad, Cuba), 1,257 quintales y que se exportaron, también, para España 493 quintales; en este año no aparece la palabra reportación, por lo que no sabemos si realmente fue una exportación de origen autóctono de la Nueva España o bien una reportación del café proveniente de Cuba.

Por cierto, en el texto de Pérez (2013:166), se mencionan las exportaciones de 1802 y 1804 y las importaciones de 1802 a1808, no obstante, hay un error en sus cifras porque en lugar de poner los quintales pone el valor de los quintales (en pesos), es decir, dice que en 1802 se exportaron 4,360 quintales, cuando en realidad fueron 272 , tal y como lo vimos más arriba, y el valor de esos quintales equivalían a 4,360 pesos. Y de esta forma ocurrió lo mismo con la demás información que proporciona.

\footnotetext{
${ }^{2}$ Quintal es equivalente a 46.008 kgs.

${ }^{3}$ Cálculos propios con información de Humboldt y gráfica 1.

${ }^{4}$ Proveniente de una familia de comerciantes, fue uno de los miembros más brillantes de la generación de la Reforma y ministro de Relaciones Exteriores durante buena parte del gobierno del presidente Benito Juárez, posteriormente ocupó la presidencia de México durante el periodo de 1872 a 1876.

${ }^{5}$ Proveniente de una familia de comerciantes, fue uno de los miembros más brillantes de la generación de la Reforma y ministro de Relaciones Exteriores durante buena parte del gobierno del presidente Benito Juárez, posteriormente ocupó la presidencia de México durante el periodo de 1872 a 1876.
}

Gráfica 1.

Importaciones de café, 1784-1818.

(Toneladas)

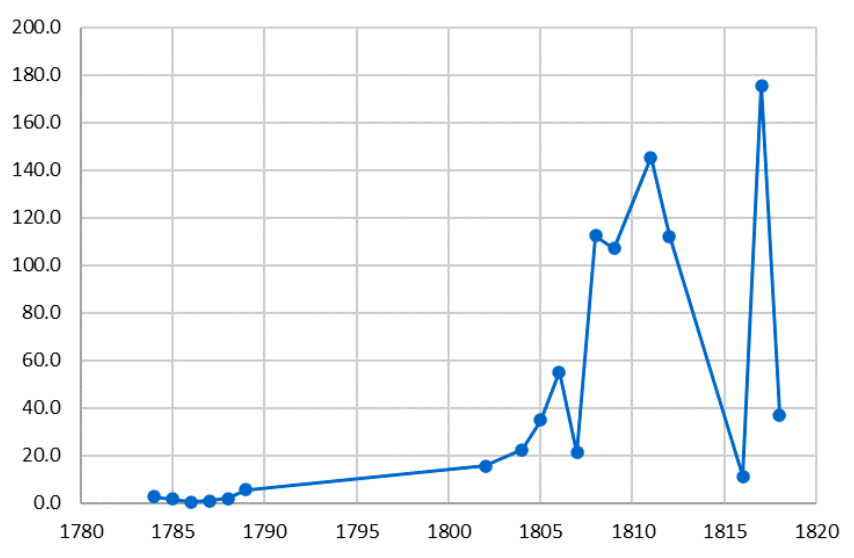

Fuente: Elaboración con datos de Gaceta de México, 1784-1789, y Lerdo de Tejada, 1802-1818, (1967).

Por otro lado, en el periódico El Águila Mexicana fechado el 20 de septiembre de 1824 se anunció la inauguración de un café en la Ciudad de México:

En la esquina del Colegio de las Niñas se ha abierto ayer un café, nombrado República Mexicana: en él se servirá con decencia toda clase de efectos (de superior calidad) anecsos a su comercio. El público generoso será el que califique lo que se promete (El Águila mexicana, 1824).

Este anuncio nos muestra una de las primeras cafeterías instaladas en México y quizá en América Latina.

En otro sentido, a principios del siglo XIX, Juan Antonio Gómez trasladó el café de la Habana a México y se plantaron algunos arbustos en Córdoba. En 1826 se contaban 500 mil arbustos que producían un fruto superior al de Cuba, y poco después, se hicieron plantaciones en Acayucan y en otros distritos del estado de Veracruz. Casi al mismo tiempo se introdujo el cultivo del café en los Estados del Sur (Romero, 1893: 138). En 1892 México ya ocupaba el sexto lugar a nivel internacional en la producción de café (Tabla 2).

\section{El café en Chiapas}

En 1804, el migrante inglés John McGee, adquirió una finca en el Soconusco, específicamente en Tuxtla Chico, a la que denominó "La Chácara"6. Su propósito era sembrar café en su finca de más de 120 hectáreas $^{7}$. Por otro lado, Ancheyta (2018:47) sostiene que la planta de café fue introducida en el 
Soconusco, en 1824, por el británico John McGee. Hay una diferencia en la fecha en ambas fuentes. McGee había sembrado café en Guatemala antes de su establecimiento en las fincas de Chipas (Olivera, 2005:304).

Tabla 2.

Principales productores de café en 1892

\begin{tabular}{lll}
\hline Lugar & Cantidad & Medida \\
\hline Brasil & $7,425,000$ & Sacos \\
Venezuela & 750,000 &, \\
Java & 750,000 &, \\
Guatemala & 500,000 &, \\
Haití & 450,000 &, \\
México & 350,000 &, \\
Posesiones inglesas: Indias & 300,000 &, \\
Orientales y Manila, etc. & & \\
Costa Rica & 250,000 &, \\
Cuba, Puerto Rico y posesiones & 250,000 &, \\
ing. en Ind. Occi. & 100,006 &, \\
Africa, Mocca & 100,000 \\
Ceylán & 69,500 &,$"$ \\
Padang & 45,000 &,$"$ \\
Macassar, Timor etc &
\end{tabular}

Fuente: Semana mercantil (1892:217).

Por su parte, Romero (1893: 139), señala que los plantíos de café en la región del Soconusco se debieron a los esfuerzos del industrioso italiano Jerónimo Manchinelly, quien sembró 1,500 matas en la Chácara, y que los pies del café fueron traídos del pueblo de San Pablo, de la República de Guatemala. ${ }^{8}$

\section{Gráfica 2.}

Producción de café en Chiapas, 1892-1906. (Toneladas)

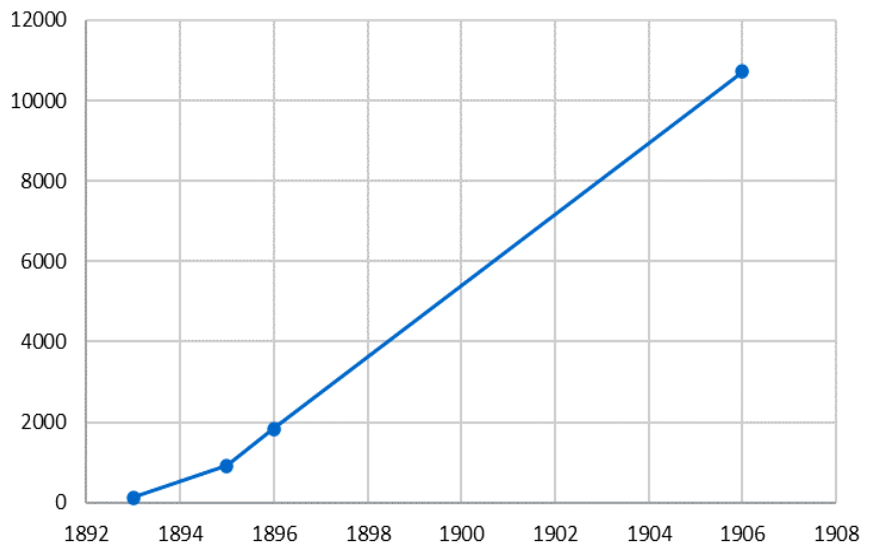

Fuente: Anuario Estadístico de la República Mexicana (1893, 1895, 1896 y 1906).
En el periódico oficial de Chiapas, con fecha 25 de junio de 1887, se indicaba que su gran riqueza era la agricultura. Sin embargo, se hallaba muy atrasada y señalaba que no existían datos estadísticos acerca de la producción agrícola que fueran exactos. Mostró datos y subrayó que eran muy aproximados. Los datos acerca de la producción anual agrícola, en kilogramos, eran los siguientes: alverjón 200,000; añil 36,000; arroz 496,000; cacao 400,000, café 362,000 ; chile $1,620,600$; frijol 2,780,000; lenteja 270,000; maíz 46,700,000; patatas 270,000; tabaco 19,000 y zarzaparrilla $32,000^{9}$. Observamos que se produjeron 362 toneladas de café, no obstante, casi una década después, es decir, en 1896 su producción tuvo un crecimiento de $500 \%$, alcanzando la cifra de $2900 \%$ en el año de 1906 . ¿A qué se debió ese crecimiento?

Antes de responder a esta pregunta tenemos que decir que en Chiapas producían este producto básico, pero sin duda, quien más sobresalía era la región sur de Chiapas, es decir, el Soconusco que producía el $75 \%$ de la producción total del estado (Tabla 3). Su producción total, en valor, fue de $1 \mathrm{mi}-$ Ilón 76 mil 400 pesos, cifra que constituyó el 88.5 del valor total producido en el estado de Chiapas. A nivel nacional el estado tuvo una participación de $15.8 \%$ en el valor total producido de café, después de Veracruz $(36.1 \%)$ y Oaxaca $(28.1 \%)^{10}$. Los tres estados constituyeron el $80 \%$ en 1896 . De esta forma, tenemos que, en 1896, el café, ya formaba un ramo agrícola de suma importancia para algunos estados de la República.

Entonces, ¿a qué se debió el aumento de la producción de café en Chiapas? Este obedeció básicamente a dos factores: el bajo costo de las tierras

\footnotetext{
${ }^{6}$ El Soconusco es una región costera que se encuentra al sur de Chiapas e históricamente ha sido el punto de unión entre México y Centroamérica y paso obligado de hombres y mercancías. Actualmente son 16 los municipios que pertenecen al Soconusco: 1) Acacoyagua, 2) Acapetahua, 3) Cacahoatán, 4) Escuintla, 5) Frontera Hidalgo, 6) Huehuetán, 7) Huixtla, 8) Mapastepec, 9) Mazatán, 10) Metapa, 11) Villa Comaltitlán, 12) Suchiate, 13) Tapachula, 14) Tuxtla Chico, 15) Tuzantán y 16) Unión Juárez.

${ }^{7}$ http://tuxtlachicomagico.blogspot.com/2013/01/lachacara 31.html, consultado el 25 de marzo de 2020.

${ }^{8}$ Romero no especificó la fecha exacta en que sucedió este acontecimiento. Sin embargo, en la página de internet indicada en la nota de página N.5 se señala que fue en el año de 1846.

${ }^{9}$ Periódico oficial del estado de Hidalgo, 25 de junio de 1887.

${ }^{10}$ Datos calculados con información Anuario Estadístico de la República Mexicana, 1897:553-559.
} 
para cultivar y el incremento de la inversión extranjera.

\section{El bajo costo de las tierras para cultivar}

Antes de ver el precio de las tierras en Chiapas, veremos el precio de algunas tierras en otros estados de la República Mexicana, para ello utilizaremos información de algunos periódicos norteamericanos que dan cuenta acerca de la baratura de las tierras en México. El periodista Russ House (1876) escribió lo siguiente:

Hemos sido amablemente favorecidos con la visita de Samuel Norris, antiguo propietario del famoso "Rancho Norris", cerca de Sacramento. El Sr. Norris ha regresado recientemente de México, donde ha estado en una visita de exploración por muchos miles de millas. Da una descripción muy interesante de la condición de México, de sus ricas tierras y del bajo precio al que venden, desde cinco hasta veinticinco centavos por acre ${ }^{11}$ (pag.1).

Por otro lado, el periodista E. Grotkass (1877:274), un año después, en 1877, escribió un artículo titulado "La agricultura en México", en él señalaba que para una colonia norteamericana, las tierras se podían comprar en condiciones fáciles, para dividirse en granjas, y que el precio de la tierra era de 25 a 50 centavos por acre, según las instalaciones y calidades de agua.

En el periódico mexicano El tiempo del 14 de abril de 1894 apareció una carta de un cafetero llamado Carlos Gris, originario del estado de Zacatecas ${ }^{12}$ que dirigía al director del periódico en la Ciudad de México y le indicaba que el hombre que intentara sembrar café se tenía que hacer, generalmente, algunas preguntas, entre las que se encontraban las siguientes: 1) ¿En dónde hallaré buen terreno para café?, 2) ¿Cuál será el precio por hectárea?, 3) Será fácil adquirir terreno o habrá que emplear en trámites una eternidad, 4) Será fácil la comunicación o estaré algo así, cómo fuera del planeta?, entre otras. En relación con el precio por hectárea, de la tierra, indicaba que en Oaxaca "se consiguen al siguiente precio": Buen terreno, hectárea 5 pesos; Muy bueno id 10 pesos" (Gris, 1894:2).

Por último, tenemos que en el periódico Blade Tribune del 28 de marzo de 1896 apareció una nota periodística llamada Coffee Growing (Cultivo de café), en la que se podía leer:

Los estadounidenses siempre están listos para aprovechar las oportunidades en el extranjero. Es este espíritu de empresa el que ahora está despertando un gran interés en el tema del cultivo de café en México...Se formó una compañía en St. Louis y se compraron 900 acres de tierra de café... el precio pagado fue de $\$ 5$ por acre... No hemos comprado la tierra con fines especulativos.

En relación con el precio de las tierras en Chiapas, tenemos que de acuerdo con (Tovar, 2004:236), los extranjeros, en 1880, aprovecharon las oportunidades para adquirir tierras, amparados en las legislaciones vigentes. El bajo costo de la tierra y lo redituable de la producción de café, estimuló a los foráneos para invertir en fincas rústicas. "Una hectárea valía menos de un peso y el costo de la producción del café era de siete centavos y se vendía a más de veinte" (Spenser, 1998:72). Según Rus (2005:253), el precio de la tierra era de 2 pesos por hectárea a mediados de 1890. Romero (1893:14) señalaba que una de las ventajas para el cultivo del café en el Soconusco era la facilidad de adquirir terrenos y su baratura. De acuerdo con Romero el costo de una hectárea, en el Soconusco, era de 25 centavos.

En 1897 apareció, en el periódico oficial de Chiapas, una nota, en la cual se podía leer lo siguiente:

En el Estado de Chiapas hay terrenos tan propicios para la siembra del café, como pueden serlo los de Cuba, y esto está atrayendo a dicho estado un gran número de cafeteros extranjeros que están adquiriendo a muy bajos precios ricos mantos de tierra. El peonaje es abundante y los jornales que se pagan a los trabajadores son bastante reducidos (Periódico Oficial del Estado de Chiapas, 1897:2).

Con la información vertida y tomando como referencia el precio por hectárea que nos proporciona Romero (1893:14), podemos concluir que el precio de la tierra por hectárea en el Soconusco, Chiapas, era más barato que otras regiones de México y en particular de Colima y sobre todo de Oaxaca. La baratura de la tierra motivo la migración hacia el Soconusco de alemanes, estadounidenses, españoles, japoneses, italianos y guatemaltecos ${ }^{13}$.

\footnotetext{
11 acre $=0.40$ hectáreas. Por otro lado, las tierras a que hace referencia el Sr. Norris, son las tierras del Estado de Colima, en donde también se cultivaba y sembraba café.

12 Escalona (2008: 56), nos menciona en su trabajo que Carlos Gris era originario de Zacatecas.

${ }^{13}$ Con relación a los migrantes se puede ver el excelente trabajo que realizó Tovar (2004) y del cual ya nos referimos más arriba.
} 


\section{Inversión extranjera}

En 1895 la población de Chiapas era de 319,599, mientras que la población extranjera llegó a la cifra de 12,441 (Secretaría de economía, 1956: 34). Por otro lado, el Censo del 28 de octubre de 1900, contabilizó un total de 363,607 pobladores en Chiapas, de los cuales 35,593 habitaban en el Soconusco, y de estos 2,032 eran extranjeros poseedores de tierras (Periódico Oficial del estado de Chiapas 5 de enero de 1901, p. 3. ). Este dato muestra la afluencia de extranjeros que llegaron a Chiapas, muchos de los cuales fueron dueños de propiedades agrícolas, cuestión que explica el crecimiento del número de haciendas en el estado en comparación a otras partes de la República (Tabla 4):

Tabla 4

Haciendas en México, 1877, 1900 y 1910

\begin{tabular}{llll}
\hline Entidad & $\mathbf{1 8 7 7}$ & $\mathbf{1 9 0 0}$ & $\mathbf{1 9 1 0}$ \\
\hline Total & 5869 & 5932 & 8431 \\
Campeche & 130 & 179 & 147 \\
Chiapas & 98 & 518 & 1076 \\
Chihuahua & 123 & 158 & 222 \\
Guanajuato & 421 & 428 & 511 \\
Hidalgo & 157 & 191 & 208 \\
Jalisco & 385 & 358 & 471 \\
México & 389 & 376 & 398 \\
Nuevo León & 247 & 435 & 507 \\
Oaxaca & 116 & 151 & 191 \\
San Luis Potosí & 159 & 155 & 211 \\
Sonora & 112 & 237 & 314 \\
Tabasco & 67 & 414 & 634 \\
Veracruz & 237 & 360 & 159 \\
Yucatán & 1145 & 52 & 1170 \\
\hline
\end{tabular}

Fuente: Secretaría de economía (1956: 41).

Un tema que está íntimamente relacionado con la propiedad privada, las haciendas y las fincas es, sin duda, la inversión extranjera directa. De esta, Soconusco superaba con creces a las demás regiones en el momento de la inversión de capital extranjero (Tabla 5). Soconusco se desarrolló como consecuencia de la expansión del cultivo del café de finales del siglo XIX. Contando con la inversión de capital extranjero, principalmente alemán (Tabla 6 y 7 ).

Los alemanes llegaron a Soconusco a finales del siglo XIX desde Guatemala, en donde se habían establecido en los años setenta. La región del Soconusco era la prolongación de la costa de Guate- mala, en donde los alemanes probaron lo fructífero que era invertir en la producción y exportación de café.

Tabla 5

Valor del capital extranjero invertido en fincas rusticas en Chiapas en 1909

(Pesos)

\begin{tabular}{lll}
\hline Departamento & Valor & Porcentaje \\
\hline Soconusco & $4,410,525$ & 46.91 \\
Palenque & $2,146,793$ & 22.83 \\
Chilón & 988,383 & 10.51 \\
Tonalá & 908,707 & 9.67 \\
Tuxtla & 557,986 & 5.93 \\
Pichucalco & 171,070 & 1.82 \\
Simojovel & 121,295 & 1.29 \\
Chiapas & 52,836 & 0.56 \\
Mariscal & 38,400 & 0.41 \\
Las Casas & 5,750 & 0.06 \\
La libertad & 200 & 0.00 \\
Total & $9,401,945$ & 100.00 \\
\hline
\end{tabular}

Fuente: Anuario Estadístico del estado de Chiapas (1911: 95-102), Tuxtla Gutiérrez.

A continuación, se presenta a los inversores más grandes de las regiones del Soconusco y de Palenque, los alemanes y los norteamericanos. Los alemanes que llegaron a tener mayor capital e importancia en el Soconusco fueron: Johannes Lutmann, Juan Pohlenz- Johannes Luttmann Guillermo Henkel, Pablo Hintze, Guillermo Kahle. En la tabla 7, apreciamos el nombre de sus fincas; así como su valor en pesos. Las fincas de Juan Pohlenz y Johannes Luttmann en 1903, tenían un valor de 178,000 pesos, mientras que las propiedades de Lutmann, en 1910, tuvieron un valor de 40,700; Guillermo Kahle era propietario de las fincas cafetaleras Germania y Hannover, con un valor fiscal de \$ 346,000 entre ambas; mientras que la capitalización que obtuvo Pablo Hintze, en 1912, le permitió incursionar en el sector agropecuario, al adquirir 626 hectáreas en Ulapa y Nueva Ulapa, con un valor fiscal de $\$ 59,900$ pesos

\footnotetext{
${ }^{14}$ La mayoría de los administradores de las fincas eran alemanes y se capitalizaron al transcurrir los años y comenzaron a trabajar por cuenta propia. Tales fueron los casos de Juan Pohlenz, Eric Edelmann y Guillermo Kahle. Los tres habían sido empleados de la casa comercial Johannes Luttmannn. Pohlenz primero se asoció con Luttmann y después compró las propiedades que estaban a su cargo.

${ }^{15}$ Valores obtenidos de Tovar (2004:239-245).
} 
El origen del café en México y el incremento de su producción en Chiapas, 1893-1920

Elías Gaona Rivera, Angélica María Vázquez Rojas y Eduardo Rodríguez Juárez

Tabla 6

Valor del capital extranjero por origen nacional invertido en fincas rústicas en Chiapas en 1909

(Pesos)

\begin{tabular}{llllll}
\hline Departamento & U.S.A & Español & Alemán & Inglés & Francés \\
\hline Soconusco & $1,227,120$ & 930,130 & $1,373,115$ & 464,814 & 335,175 \\
Palenque & $1,614,285$ & 36,270 & 229,660 & $/$ & $/$ \\
Chilón & 11,050 & 792,440 & 184,893 & $/$ & $/$ \\
Tonalá & 545,027 & 361,740 & $/$ & $/$ & $/$ \\
Tuxtla & 25,408 & 128,418 & $/$ & 400,000 & 1,100 \\
Pichucalco & 11,600 & 132,820 & $/$ & $/$ & 20,000 \\
Simojovel & $/$ & 79,075 & 19,850 & $/$ & 19,200 \\
Chiapa & $/$ & 16,036 & $/$ & $/$ & $/$ \\
Mariscal & $/$ & 33,200 & $/$ & 5,200 & $/$ \\
Mezcalapa & 9,810 & $/$ & $/$ & $/$ & 17,460 \\
Las Casas & $/$ & 5,010 & $/$ & 650 & $/$ \\
La libertad & $/$ & 200 & $/$ & $/$ & $/$ \\
\hline
\end{tabular}

Fuente: Anuario Estadístico del estado de Chiapas (1911: 95-102), Tuxtla Gutiérrez.

\section{Tabla 7}

Finqueros, fincas y su valor

(Pesos)

\begin{tabular}{|c|c|c|c|c|}
\hline Nombre & Lugar & Hectáreas & Producto & Valor pesos \\
\hline \multicolumn{5}{|c|}{ Pohlenz-Luttmann, 1903.} \\
\hline \multicolumn{5}{|l|}{ Fincas } \\
\hline Bremen & \multicolumn{3}{|l|}{ Motozintla } & 22,000 \\
\hline Lubeca & \multirow{2}{*}{\multicolumn{3}{|c|}{$\begin{array}{l}\text { Motozintla } \\
\quad \text { Guillermo Henkel, } 1906 .\end{array}$}} & 156,000 \\
\hline & & & & \\
\hline \multicolumn{5}{|l|}{ Fincas } \\
\hline Santa Anita & & 213 & Café & 16,570 \\
\hline Morelia & & 100 & Café & 14,000 \\
\hline \multirow[t]{2}{*}{ San Carlos } & & 157 & Maíz y café & 21,300 \\
\hline & \multicolumn{3}{|c|}{ Lutmann, 1910.} & \\
\hline \multicolumn{5}{|l|}{ Fincas } \\
\hline Nombre & Lugar & Hectáreas & Producto & Valor pesos \\
\hline Hamburgo & Tapachula & 427 & Café & 12,300 \\
\hline Sonora & Tapachula & 492 & Maíz & 15,100 \\
\hline Innominada & $\begin{array}{l}\text { Cacahua- } \\
\text { tán }\end{array}$ & & Café & 1,270 \\
\hline Innominada & Tunazatán & & Cereales & 12,030 \\
\hline
\end{tabular}

Continúa... 
El origen del café en México y el incremento de su producción en Chiapas, 1893-1920

Elías Gaona Rivera, Angélica María Vázquez Rojas y Eduardo Rodríguez Juárez

Guillermo Kahle, 1911.

Fincas

Germania

1075

Café

124,000

Hannover

302

Café

222,000

Fincas

Uluapay Nueva Uluapa

626

59,900

Santa Elena

Pablo Hintze, 1912.

La libertad

Escuintla

Fuente: Elaboración con información de Tovar (2004: 239-245).

En relación con el valor de las propiedades de los norteamericanos, en 1907, destacan las de los siguientes ciudadanos: Carlos Lesher (1, 423,350), Fernando Braun (112,500), Federico Quinby $(71,700)$, Luis Brewer $(29,500)$. El valor total de las fincas ascendía a 1,637,050. La finca más importante de Lesher era la de San Carlos con un valor de 1,322,150; otras de sus fincas fueron: Los Tocayos, El Carmen, El Arenal, San José Aguayal, Toayos, San Francisco y Las Delicias. La finca más importante, de las dos, que tenía Quinby era la de Doña María con un valor de 50,000 pesos, la otra finca era la de Santa Lucia. Por otro lado, la finca más importante de Luis Brewer fue la de Guatimoc con un valor de 10,000 pesos (Tovar, 2004: 250).

Escalona (2008:54), nos dice que los primeros finqueros cafetaleros dejaron su lugar a grandes consorcios como la German American Coffee Co., con una inversión de 5 millones de pesos. Para la década de 1920, las tierras de propiedad estadounidense, en México, fueron valoradas en alrededor de $\$ 140$ millones. Una de las empresas incluidas en ese valor era la German-American Coffee Company, que poseía cuatro diferentes extensiones de tierra en todo Chiapas (Winters, 2014:238). ${ }^{16}$

Esta empresa incorporada, en 1903, fue la segunda más importante inversión de capital de América del Norte en Chiapas, era propiedad exclusiva de estadounidenses, excepto William Fahrholz, que era ciudadano alemán y administraba la empresa. El nombre de la empresa probablemente tuvo su origen en el hecho de que algunos de los organizadores eran personas de origen alemán y que prácticamente todos los propietarios eran ciudadanos esta- dounidenses (Winters, 2014:240).

Gracias a esas inversiones se pudieron realizar exportaciones de café al resto del mundo. Un periódico de la época, daba cuenta de ello:

En Chiapas se presentan muy abundantes las cosechas de café. Sabemos que solamente un cosechero ha dado principio a sus exportaciones con un envío de 300 quintales y espera que el total de la rendición de su finca sea de más de 6000 quintales $^{17}$ (La voz de México, 1896: 3).

Desafortunadamente no se cuenta con información de las exportaciones de café que realizaron los estados, no obstante, si disponemos de información a nivel país para darnos una cuenta de su evolución (Tabla 8), dado que Chiapas, en 1895, ocupaba el cuarto sitio después de Oaxaca, Veracruz y Puebla $^{18}$.

Entre 1888 y 1895 el $94.7 \%$ de las exportaciones de café tenían como destino los Estados Unidos. En 1888 constituyó el 76.5 y pasó a 97.4 en $1894^{19}$. De esta forma, tenemos que el bajo costo de las tierras en Chiapas, el arribo de inversión extranjera y el incremento de la demanda externa del café, contribuyeron a incrementar la producción de éste producto.

\footnotetext{
${ }^{16}$ La compañía estaba ubicada físicamente en Triunfo, Salto de Agua, en el distrito de Palenque

${ }^{17}$ Palenque 300 quintales $=13.8$ toneladas; 6000 quintales $=276$ toneladas.

${ }^{18}$ Información obtenida del Anuario Estadístico de la República Mexicana (1897:553).

${ }^{19}$ Cifras calculadas con información del diario Semana mercantil (1895) y Escalona (2008).
} 
Tabla 8

Exportaciones de café a varios países, 1890-1891 (Toneladas)

\begin{tabular}{ll}
\hline \multicolumn{2}{c}{$\mathbf{1 8 9 0}$} \\
\hline Estados Unidos & 9,201 \\
Alemania & 307 \\
Francia & 259 \\
Inglaterra & 120 \\
Holanda & 22 \\
España & 20 \\
Total & 9,929 \\
\multicolumn{1}{c}{} \\
Estados Unidos & 13,719 \\
Francia & 461.3 \\
Alemania & 389.5 \\
Inglaterra & 81.8 \\
España & 4.6 \\
Colombia & 0.2 \\
Italia & 0.1 \\
Total & 14,656 \\
\hline
\end{tabular}

Fuente: Elaboración con datos de Semana mercantil (1895:219).

\section{Conclusiones}

El café mexicano tuvo como origen el proveniente de Cuba. Gracias a las importaciones de café de Cuba, el pueblo mexicano pudo consumir café, durante el periodo novohispano e inmediatamente posterior a la independencia de México. Se tienen noticias de que su siembra se inició en la Nueva España alrededor de 1790. En el año de 1824 se estableció una de las primeras cafeterías en la Ciudad de México.

Hay noticias de que el país realizó sus primeras exportaciones de café en 1802 y 1804, aunque seguramente no eran productos autóctonos, sino que formaban parte de las importaciones que provenían de Cuba.

A principios del siglo XIX, Juan Antonio Gómez trasladó el café de la Habana a México y se plantaron algunos arbustos en Córdoba (Veracruz). Casi al mismo tiempo se introdujo el cultivo del café en Chiapas. En 1892 México ya ocupaba el sexto lugar a nivel internacional en la producción de café, siendo Chiapas uno de los principales de la República Mexicana.
Chipas se posicionó como uno de los principales productores de café debido a dos razones: el bajo costo de la tierra para cultivar y el arribo de inversión extranjera, fundamentalmente estadounidense y alemana.

\section{Bibliografía}

Ancheyta, C. (2018). Caficultura y flexibilidad del mercado de trabajo en una región transfronteriza: México -Guatemala. Tesis. Departamento de Ciencias Sociales y Humanidades. Dirección General de Investigación y Posgrado. Tuxtla Gutiérrez: Universidad Autónoma de Chiapas.

Daily Alta California. (6 de octubre de 1853). Coffee. Its Production and Consumption. https:// cdnc.ucr.edu/cgi-bin/cdnc? $a=d \& d=D A C 18531006 \&$

Dzul, M. (2020). Unidad3. Aplicación de los métodos científicos. "Método histórico". Pachuca: Universidad Autónoma del Estado de Hidalgo, en https://www.uaeh.edu.mx/docencia/

VI_Presentaciones/

licenciatura_en_mercadotecnia/ fundamentos_de_metodologia_investigacion/ PRES40.pdf, consultado el día 22 de septiembre de 2020.

El Águila Mexicana. (20 de septiembre de 1824).

Escalona, H. (2008). El desarrollo de la caficultura en México y los extranjeros en la segunda mitad del siglo XIX: una aproximación para su estudio. Tesis. Universidad Pablo de Olavide de Sevilla. Programa de doctorado, Europa el mundo mediterráneo. Sevilla: Universidad Pablo de Olavide de Sevilla.

Gris, C. (14 de abril de 1894, pág. 2.). Carta de Carlos Gris. El tiempo.

Grotkass, E. (5 de mayo de 1877, pág. 274). Agriculture in Mexico. Pacific Rural Press.

House, R. (13 de abril de 1876, pág. 1). Colima Coffee. California Farmer and Journal of Useful Sciences, Vol. 45, Num. 3, consultado en https://cdnc.ucr.edu/?

$$
a=d \& d=C F 18760413.2 .2 \& e=-------e n--20--1--
$$
txt-txIN-------1

Humboldt, A. (1822). Ensayo político sobre el reino de la Nueva España. Tomo II. París: J. Smith.

La voz de México. (6 de diciembre de 1896, pág. 3) 


\section{El origen del café en México y el incremento de su producción en Chiapas, 1893-1920}

Elías Gaona Rivera, Angélica María Vázquez Rojas y Eduardo Rodríguez Juárez

Las cosechas de café en Chiapas. La voz de México.

Langlois, C., \& Seignobos, C. (2003). Introducción a los estudios históricos. Alicante: Universidad de Alicante.

Lerdo de Tejada, S. (1967). Comercio Exterior de México, México, D.F. México: Banco Nacional de Comercio.

Ministerio de Fomento. Dirección General de Estadística. (1894, 1896, 1897 y 1907). Anuario Estadístico de la República mexicana 1893, 1895, 1886 y 1908. México: Dirección General de Estadística.

Ministerio de Fomento. Dirección General de Estadística. (1897). Anuario Estadístico de la República mexicana 1896 (1 de enero, pág. 497). México: Dirección General de Estadística.

National Coffee Association (2020), The History of Coffee, en http://www.ncausa.org/about-

coffee/ history-of-coffee, consultado el 3 de febrero de 2020

Olivera, M. (2005). Chiapas: de la independencia a la revolución. México: CIESAS.

Pendergrast, M. (2010). Uncommon Grounds: The History of Coffee and How It Transformed Our World Basic Books New York. New York: Basic Books.

Pérez, P. (2013). Los siglos XIX y XX en la cafeticultura nacional: de la bonanza a la crisis del grano de oro mexicano. Revista de Historia, 159-199.

Periódico oficial de Estado de Chiapas. (25 de junio de 1887). http://www.hndm.unam.mx/consulta/ publicacion/visualizar/558075be7d1e63c9fea1a3b6? anio $=1887 \&$ mes $=06 \&$ dia $=25 \&$ tipo $=$ publicacion

Periódico Oficial del Estado de Chiapas. (18 de diciembre de 1897, pág. 2). Región cafetera. Periódico Oficial del Estado de Chiapas. http://www.hndm.unam.mx/consulta/ publicacion/ visualizar/558075be7d1e63c9fea1a3b6? anio=1897\&mes=12\&dia=18\&tipo=publicacio $\mathrm{n}$

Gobierno del Estado de Chiapas (1911). Periódico
Oficial del Estado de Chiapas (1911: 95-102).

http://www.hndm.unam.mx/consulta/

publicacion/

visualizar/558075be7d1e63c9fea1a3b6?

anio $=1911 \&$ mes $=10 \&$ dia $=28 \&$ tipo $=$ publicacion

Romero, M. (1893). Cultivo del café en la costa meridional de Chiapas. México: Oficina Tip. De la secretaría de fomento.

Rus, J. (2005). El café y la recolonización de los Altos de Chiapas, 1892-1910. En M. Olivera, Chiapas: de la independencia a la revolución (págs. 253-287). México: Publicaciones de la tía chata.

Secretaría de economía. (1956). Estadísticas sociales del porfiriato, 1877-1910. México: Talleres Gráficos de la Nación.

Semana mercantil. (9 de mayo de 1895, pág. 219) Producción, tráfico y porvenir del café.

Spenser, D. (1998). Los inicios del cultivo del café en Soconusco y la inmigración extranjera. En B. Von Mentz, R. Spenser, \& M. Pérez, Los empresarios alemanes del Tercer Reich y la oposición de derecha de Cárdenas, 2 vols (págs. 61-87). México: CIESAS.

Toussaint, M. (2012). Los negocios de un diplomático: Matías Romero en Chiapas. Latinoamérica, 129-157.

Tovar, M. E. (2004). Los Finqueros Extranjeros en el Soconusco durante el porfiriato, tesis, Facultad de filosofía y letras, Universidad Autónoma de México. México: Universidad Autónoma de México.

Valdez M. (1784-1789). Gazetas de México, 1784-

1789. http://bdh.bne.es/bnesearch/Search.do? num-

fields $=1 \&$ field $1=$ id_publicacion\&field 1 val $=0004$ 520440\&field1Op=AND\&advanced=true\&show Yearltems=true\&fillForm $=$ false \&sort=anho

Vila, M. (1997). Café amargo: por un comercio Norte-Sur más justo. Barcelona: Icaria Editorial.

Winters, A. (2014). Mexico and Expropriation: The Case of the German-American Coffee Company. Anthós: Vol. 6, 236-258. 